\title{
HUBUNGAN RESPON EMOSI KELUARGA DENGAN KEKAMBUHAN PASIEN SKIZOFRENIA DI POLIKLINIK JIWA RSJ MUTIARA SUKMA MATARAM
}

\author{
I Made Eka Santosa* \\ imadeekasantosa@gmail.com
}

\begin{abstract}
ABSTRAK
Gangguan jiwa berat terbesar di Indonesia adalah Skizofrenia yang mencapai $70 \%$ dari seluruh penderita gangguan jiwa berat. Dukungan keluarga sangat membantu proses penyembuhan pasien Skizofrenia sehingga frekuensi kekambuhan menurun. Dukungan yang paling dibutuhkan oleh pasien Skizofrenia adalah dukungan emosional yang dapat diukur dengan melihat respon emosi keluarga terhadap pasien Skizofrenia.

Penelitian ini menggunakan disain deskriptif korelasional dengan pendekatan cross sectional yang bertujuan untuk mengetahui hubungan antara respon emosi keluarga dengan kekambuhan pasien Skizofrenia. Populasi penelitian ini adalah keluarga inti yang tinggal serumah dengan pasien Skizofrenia yang sedang menjalani rawat jalan di Poliklinik Jiwa RSJ Mutiara Sukma Mataram. Teknik pengambilan sampel menggunakan Non Probability Sampling dengan teknik Accidental Sampling. Jumlah sampel sebanyak 58 orang.

Hasil penelitian menunjukan bahwa respon emosi keluarga sebagian besar menolak yaitu sebanyak 49 responden $(84,5 \%)$. Kekambuhan pasien skizofrenia sebagian besar dalam kategori kambuh yaitu sebanyak 48 responden $(82,8 \%)$. Ada hubungan respon emosi keluarga dengan kekambuhan pasien Skizofrenia dengan nilai $\mathrm{p}$ $=0,000$ lebih kecil dari derajat kesalahan $\alpha=0,05$. Disarankan kepada keluarga untuk memberikan respon emosi yang positif untuk mendukung perawatan pasien Skizofrenia.
\end{abstract}

Kata kunci : respon emosi, kekambuhan

\section{PENDAHULUAN}

Kesehatan secara umum mencakup kesehatan fisik dan kesehatan jiwa. Keduanya harus berjalan secara seimbang agar seseorang dapat menjalankan fungsinya secara optimal. Menurut Undang Undang No 18 Tahun 2014 tentang Kesehatan Jiwa, kesehatan jiwa merupakan kondisi dimana seorang individu dapat berkembang secara fisik, mental, spitirual dan sosial sehingga individu tersebut menyadari kemampuan sendiri, dapat mengatasi tekanan, dapat bekerja secara produktif, dan mampu memberikan kontribusi untuk komunitasnya. Dalam PPDGJ III diuraian bahwa gangguan jiwa adalah sindrom pola perilaku yang khas berkaitan dengan suatu gejala distress atau hendaya di dalam satu atau lebih fungsi yang penting dari manusia baik fungsi psikologik, prilaku maupun biologik (Maramis, 2008). Gangguan pada kesehatan jiwa membuat seseorang menjadi tidak produktif.

Hasil Riskesdas tahun 2013 menunjukkan bahwa prevalensi gangguan jiwa berat pada penduduk Indonesia adalah 1,7 per mil. Hal ini sejaan dengan data dari Depkes tahun 2009 yang menyatakan bahwa terdapat 28 juta orang mengalami gangguan kesehatan jiwa, dimana 0,46\% diantaranya menderita gangguan jiwa berat. Gangguan jiwa berat terbesar di 
Indonesia adalah Skizofrenia yang mencapai $70 \%$ dari penderita gangguan jiwa berat. Prevalensi penderita Skizofrenia di Indonesia adalah 0,3-1\% dan biasanya muncul pada usia produktif. Data WHO (2013) menunjukkan bahwa sebanyak 450 juta penduduk dunia menderita Skizofrenia, $35 \%$ mengalami keambuhan, 20-40\% diobati di rumah sakit, 15-20\% melakukan percobaan bunuh diri dan $10 \%$ diantaranya meninggal karena bunuh diri.

Skizofrenia merupakan sindrom kompleks yang dapat menimbulkan efek yang merusak baik pada diri sendiri maupun orang lain dengan ciri khas disorganisasi pada pembicaraan, pikiran, dan gerakan psikomotorik (Isaacs, 2004). Skizofrenia merupakan bentuk psikosa fungsional dengan gangguan utama pada proses pikir dan terjadinya keretakan atau perpecahan antara proses pikir, emosi, kemauan dan psikomotor disertai dengan gangguan kenyataan yang disertai waham dan halusinasi (Hawari, 2003, Yosep \& Sutini, 2015). Penyakit Skizofrenia ini sering kambuh dan menjadi kronis apabila pasien tidak mendapatkan penanganan yang baik serta kurang mendapatkan dukungan dari keluarga maupun lingkungan sekitarnya. Diperlukan daya dukung yang optimal bagi kesembuhan pasien Skizofrenia.

Pasien Skizofrenia yang dirawat di Rumah Sakit Jiwa Provinsi NTB pada tahun 2019 berdasarkan data dari IGD RSJ Mutiara Sukma antara lain : Skizofrenia Paranoid sebanyak 1016 (60,5\%), Skizofrenia Tak Terinci 94 $(5,56 \%)$, Skizofrenia YTT $83(4,91 \%)$, Skizofreina Tipe Manik 54 (3,19\%), Skizofrian Hebefrenik 17 (1\%). Pasien Skizofrenia ini banyak yang mengalami kekambuhan dengan frekuensi kekambuhan lebih dari 2-3 kali, bahkan ada yang sampai 6-7 kali dirawat di RSJ Mutiara Sukma dengan keluhan yang sama.
Ada banyak faktor penyebab kekambuhan pasien skizofrenia, salah satunya adalah dari faktor dukungan keluarga yang terkait dengan respon emosi keluarga terhadap penderita skizofrenia. Menurut Raharjo, Rochmawati dan Purnomo (2014) dalam Nuraini (2018), faktor pemicu kekambuhan pasien Skizofrenia antara lain ketidakpatuhan minum obat, stressor pekerjaan, kondisi isolasi sosial, status ekonomi, termasuk dukungan dan penerimaan keluarga.

Kebutuhan pasien gangguan jiwa khususnya penderita Skizofrenia adalah adanya dukungan, perhatian, pengertian dan kasih sayang dari orang-orang terdekatnya, khususnya dari keluarga. Dukungan keluarga sangat membantu proses penyembuhan pasien Skizofrenia sehingga frekuensi kekambuhan bisa ditekan sedemikian rupa atau bahkan tidak kambuh kembali. Dukungan keluarga ini sejalan dengan konsep dukungan sosial yang terbagi menjadi 4 dimensi yaitu dukungan emosional, dukungan informatif, dukungan instrumental, serta dukungan penghargaan (Kemenkes RI, 2018). Dukungan yang paling dibutuhkan oleh pasien Skizofrenia agar dapat menjalani proses penanganan penyakitnya adalah dukungan emosional. Dukungan emosional keluarga dapat diukur dengan melihat respon emosi keluarga terhadap anggota keluarganya yang menderita Skizofrenia.

Menurut Kubler \& Ross (2005), respon emosi seseorang terhadap penyakit kronis atau penyakit terminal meliputi respon menolak, marah, tawar menawar, depresi dan menerima. Respon emosi ini juga dialami oleh keluarga dimana responnya tidak selalu sinkron antara keluarga dan pasien. Sedangkan menurut Hudak \& Gallo (1998), respon emosi terhadap kehilangan meliputi: (1) tahap terkejut dan tidak percaya, (2) 
mengembangkan kesadaran, (3) tahap restitusi, (4) tahap resolusi.

Respon emosi keluarga dapat disederhanakan menjadi 2 yaitu respon emosi menolak (perasaan malu, tidak percaya, bingung, takut dan tidak mau mencari bantuan kesehatan) dan respon emosi menerima (penerimaan kondisi klien, mengambil keputusan yang tepat untuk pengobatan klien). Respon emosi keluarga yang mau menerima sangat diperlukan dalam mencegah kekambuhan klien skizofrenia, karena setelah klien dinyatakan sembuh, dari pihak rumah sakit memulangkan klien ke lingkungan keluarga dan umumnya dalam beberapa hari, minggu atau bulan di rumah, kembali dirawat dengan alasan perilaku klien yang tidak dapat diterima oleh keluarga dan lingkungan. Kualitas dan efektifitas keluarga yang memadai akan membantu dalam proses mencegah terjadinya kekambuhan klien skizofrenia (Keliat, 1996). Karena itu, peneliti tertarik untuk mengetahui hubungan antara respon emosi keluarga dengan kekambuhan pasien Skizofrenia di Poliklinik Jiwa RSJ Mutiara Sukma Mataram

\section{METODOLOGI PENELITIAN}

Penelitian ini dilaksanakan di RSJ Mutiara Sukma pada bulan Maret 2020 dan yang menjadi subyek penelitian adalah keluarga yang salah satu anggota keluarganya menderita skizofrenia di Poliklinik Jiwa.

1. Populasi

Populasi dalam penelitian ini adalah semua keluarga inti (salah satu suami/istri, ayah/ibu, dan anak) yang tinggal serumah dengan pasien Skizofrenia yang berkunjung ke Poliklinik Jiwa RSJ Mutiara Sukma Mataram pada bulan Maret 2020.

2. Sampel

Sampel dalam penelitian ini adalah keluarga inti (salah satu suami/istri, ayah/ibu, dan anak) yang tinggal serumah dengan pasien Skizofrenia yang sedang menjalani rawat jalan di Poliklinik Jiwa RSJ Mutiara Sukma Mataram. Jumlah sampel yang didapatkan pada saat penelitian sebanyak 58 orang.

3. Teknik Sampling

Teknik pengambilan sampel dalam penelitian ini menggunakan metode Non Probability Sampling dengan teknik Accidental Sampling yaitu pengambilan sampel atau responden yang kebetulan ada atau tersedia (Notoatmodjo, 2003).

4. Desain Penelitian

Penelitian ini adalah penelitian deskriptif korelasional dengan menggunakan pendekatan cross sectional

5. Identifikasi Variabel dan Definisi Operasional

a. Variabel Independen : Respon Emosi Keluarga

Definisi : Kondisi perasaan keluarga yang merawat dan tinggal satu rumah dengan pasien skizofrenia dalam kaitannya dengan kondisi yang dialami pasien.

Parameter : respon emosi menolak : perasaan malu, tidak percaya, bingung, takut dan tidak mau mencari bantuan kesehatan (skor > 15), Respon emosi menerima : penerimaan kondisi klien, mengambil keputusan yang tepat untuk pengobatan klien $($ skor $=15)$

b. Variabel Dependen : Kekambuhan pasien Skizofrenia

Definisi : Pasien datang ke rumah sakit lebih dari satu kali dengan diagnosa yang sama seperti sebelumnya

Parameter : Klien skizofrenia yang datang lebih dari satu kali dan menunjukkan gejala yang sama seperti sebelumnya dengan 
katagori kambuh skor 1 dan tidak kambuh skor 0

6. Instrumen Penelitian

Untuk mengetahui respon emosi keluarga digunakan kuesioner dengan 15 pertanyaan tentang respon emosi keluarga yang meliputi perasaan malu, tidak percaya, bingung, takut, serta keputusan dalam mencari bantuan kesehatan. Sedangkan untuk mengetahui kekambuhan pasien skizofrenia dengan wawancara kepada keluarga kemudian divalidasi dengan melihat rekam medis pasien.

7. Lokasi dan Waktu Penelitian

c. Lokasi penelitian

Penelitian ini dilaksanakan di

Poliklinik RSJ Mutiara Sukma

Mataram

d. Waktu Penelitian

Penelitian ini dilaksanakan pada tanggal 1 - 31 Maret 2020

8. Analisa Data

Untuk mengetahui signifikan (nilai p) hubungan antara variabel terikat yaitu kekambuhan pasien skizofrenia dengan variabel bebas yaitu respon emosi keluarga, dilakukan uji statistik menggunakan uji Chi square dengan menggunakan SPSS dengan tingkat kepercayaan 5\% $(0,05)$.

\section{HASIL PENELITIAN}

\section{Respon Emosi Keluarga}

Tabel 1. Distribusi frekuensi respon emosi responden di Poliklinik Jiwa RSJ Mutiara Sukma Mataram

\begin{tabular}{|c|c|r|r|}
\hline No & $\begin{array}{c}\text { Respon } \\
\text { Emosi }\end{array}$ & Jumlah & $\%$ \\
\hline 1 & Menerima & 9 & $15,5 \%$ \\
\hline 2 & Menolak & 49 & $84,5 \%$ \\
\hline & Total & 58 & $100 \%$ \\
\hline
\end{tabular}

Tabel di atas menunjukkan bahwa sebagian besar responden penelitian mempunyai respon emosi menolak yaitu sebanyak 49 responden $(84,5 \%)$.

2. Kekambuhan pasien skizofrenia
Tabel 2. Distribusi frekuensi kekambuhan pasien skizofrenia di Poliklinik Jiwa RSJ Mutiara Sukma Mataram

\begin{tabular}{|c|l|r|c|}
\hline No & Kekambuhan & Jumlah & $\%$ \\
\hline 1 & Kambuh & 48 & $82,8 \%$ \\
\hline 2 & $\begin{array}{l}\text { Tidak } \\
\text { Kambuh }\end{array}$ & 10 & $17,2 \%$ \\
\hline & Total & 58 & $100 \%$ \\
\hline
\end{tabular}

Tabel di atas menunjukkan bahwa sebagian besar pasien skizofrenia mengalami kekambuhan yaitu sebanyak 48 responden $(82,8 \%)$.

3. Hubungan respon emosi keluarga dengan kekambuhan pasien skizofrenia

Tabel 3. Hubungan respon emosi keluarga dengan kekambuhan pasien skizofrenia di Poliklinik Jiwa RSJ Mutiara Sukma Mataram

\begin{tabular}{|c|c|c|c|c|}
\hline No & $\begin{array}{c}\text { Respon } \\
\text { Emosi }\end{array}$ & $\begin{array}{c}\text { Kam } \\
\text { buh }\end{array}$ & $\begin{array}{c}\text { Tidak } \\
\text { kambuh }\end{array}$ & \\
\hline 1 & Menerima & 5 & 4 & 9 \\
\hline 2 & Menolak & 43 & 6 & 49 \\
\hline & Total & 48 & 10 & 58 \\
\hline
\end{tabular}

Tabel di atas menunjukkan bahwa sebagian besar responden mempunyai respon emosi menolak dengan kekambuhan pasien skizofrenia dalam kategori kambuh yaitu sebanyak 43 responden $(74,13 \%)$.

Berdasarkan data tersebut, setelah dilakukan uji statistik ChiSquare diperoleh hasil nilai signifikan 0,000 lebih kecil dari derajat kesalahan $\alpha$ 0,05 (5\%), maka dapat disimpulkan bahwa ada hubungan respon emosi keluarga dengan kekambuhan pasien skizofrenia di Poliklinik RSJ Mutiara Sukma Mataram

\section{PEMBAHASAN}

\section{Respon Emosi Keluarga}

Berdasarkan hasil penelitian bahwa sebagian besar responden penelitian mempunyai respon emosi menolak yaitu sebanyak 49 responden $(84,5 \%)$. Emosi adalah manifestasi 
perasaan atau afek keluar yang disertai banyak komponen fisiologik dan berlangsung tidak lama. Menurut Coon (2005) emosi adalah suatu keadaan perasaan yang telah melampaui batas sehingga untuk mengadakan hubungan dengan sekitarnya mungkin terganggu.

Respon emosi sejalan dengan ekspresi emosi keluarga dimana respon emosi menolak setara dengan ekspresi emosi yang tinggi yang menyebabkan frekuensi kekambuhan pasien Skizofrenia semakin meningkat. Ekspresi emosi tinggi ini dapat berupa keluarga memperlihatkan emosi yang diekspresikan secara berlebihan, misalnya klien sering dimarahi, diomeli atau dilarang dan dibatasi dengan aturan yang berlebihan (Pardede, 2016).

Reaksi keluarga adalah keluarga akan mengalami perubahan peran akibat dari salah satu anggota keluarganya menderita sakit. Faktorfaktor yang mempengaruhi reaksi keluarga meliputi faktor sosial dan lingkungan yaitu lingkungan keluarga, dukungan sosial, dan pengetahuan. Sedangkan faktor internal yang meliputi kepribadian, persepsi, pekerjaan / status ekonomi, status perkawinan, dan umur.

Keluarga yang memperlihatkan respon menolak terhadap kondisi salah satu anggota keluarganya yang menderita gangguan jiwa mencerminkan perasaan tidak menerima atas kenyataan yang dialami salah satu anggota keluarganya. Peran petugas kesehatan dan lingkungan sekitar sangat berperan penting dalam memberi dukungan kepada keluarga untuk dapat merawat dan menerima anggota keluarga yang mengalami gangguan jiwa.
Dukungan keluarga juga diartikan sebagai suatu bentuk hubungan interpersonal yang melindungi seseorang dari efek stress yang buruk dan jika tidak diperhatikan aan meningkatkan kekambuhan pada pasien Skizofrenia (Kaplan \& Sadock, 2002). Dukungan keluarga adalah sikap, tindakan penerimaan keluarga terhadap anggota keluarganya, berupa dukungan informasional, dukungan penilaian, dukungan instrumental dan dukungan emosional (Friedman, 2010). Dukungan keluarga dilandasi dari respon emosi keluarga, jika respon emosi keluarga menolak maka pasien Skizofrenia kehilangan dukungan support system utama dalam perawatan penyakitnya yaitu keluarga dekatnya.

\section{Kekambuhan Pasien Skizofrenia}

Skizofrenia adalah suatu gangguan psikosis dengan etiologi yang tidak diketahui, ditandai oleh gejala psikotik yang secara berarti mengganggu fungsi dan menyangkut gangguan dalam alam perasaan, proses berpikir dan gangguan prilaku (Yosep \& Sutini, 2015). Penyakit Skizofrenia ini sering kali kronis dan kambuh, ditambah lagi dengan penyebab dan patofisiologi yang bervariasi sehingga memerlukan perawatan intensif di rumah sakit serta memerlukan dukungan dari lingkungan sekitarnya (Amelia, D.R. \& Azwar, Z (2013).

Dari hasil penelitian diperoleh hasil bahwa sebagian besar pasien skizofrenia mengalami kekambuhan yaitu sebanyak 48 responden $(82,8 \%)$. Hal ini sejalan dengan penelitian Sari (2017) yang menunjukkan bahwa pasien Skiszofrenia mayoritas mengalami kekambuhan sebanyak $67,1 \%$ yang disebabkan karena ketidakmampuan dan ketidaktahuan 
keluarga dalam menangani pasien Skizofrenia saat pasien pulang ke rumah (Tiara, 2020).

Ada beberapa faktor yang dapat memicu kekambuhan pasien skizofrenia mencakup pengetahuan keluarga terhadap hal-hal yang berkaitan dengan kesehatan, system nilai yang dianut oleh keluarga, sarana dan prasarana atau fasilitas kesehatan bagi masyarakat. Termasuk fasilitas kesehatan yaitu Puskesmas, Rumah Sakit dan Rumah Sakit Jiwa.

Wujud adanya dukungan keluarga pada penderita skizofrenia adalah keluarga yang mau memeriksakan penderita skizofrenia bukan hanya sadar akan pentingnya kesehatan jiwa tetapi juga dengan adanya kemudahan dalam mendapatkan pelayanan kesehatan jiwa. Faktor penguat meliputi faktor sikap dan perilaku petugas kesehatan. Misalnya petugas kesehatan membantu pasien dan keluarga menyesuaikan diri dari lingkungan keluarga, dalam hal sosialisasi, perawatan mandiri dan kemampuan memecahkan masalah

\section{Hubungan respon emosi keluarga dengan kekambuhan pasien skizofrenia}

Berdasarkan data respon emosi dan kekambuhan pasien Skizofrenia, setelah dilakukan uji statistik ChiSquare diperoleh hasil nilai signifikan 0,000 lebih kecil dari derajat kesalahan $\alpha$ 0,05 (5\%), maka dapat disimpulkan bahwa ada hubungan respon emosi keluarga dengan kekambuhan pasien skizofrenia di Poliklinik Jiwa RSJ Mutiara Sukma Mataram

Menurut Bleecher dikutip oleh Hawari (2003), reaksi penolakan keluarga terhadap penyakit atau setelah mengetahui diagnosis yang diderita salah satu anggota keluarganya meliputi: shopping dokter, menandai gejala dari penyakit aktual ke kondisi yang minor, menolak untuk percaya hasil pemeriksaan, menunda persetujuan perawatan, bertingkah laku sangat gembira dan optimis walaupun diagnosis telah dikatakan, menolak untuk mengatakan kepada orang lain, mendesak untuk tidak mengatakan kepada orang lain, menolak alasan untuk masuk rumah sakit, tidak menyatakan tentang diagnosis, perawatan dan prognosis.

Penolakan adalah bentuk reaksi koping mekanisme untuk melindungi diri sendiri terhadap kenyataan yang tidak menyenangkan, dengan menolak menghadapi hal itu. Tahap ini merupakan reaksi yang bisa terjadi pada keluarga yang salah satu anggota keluarganya menderita skizofrenia. Jika tahap ini terus berlanjut pada keluarga akan berdampak tidak baik bagi pasien skizofrenia sendiri ketika pasien kembali dalam lingkungan keluarga.

Respon emosi keluarga yang mau menerima sangat diperlukan dalam mencegah kekambuhan klien skizofrenia, karena setelah klien dinyatakan sembuh, dari pihak rumah sakit memulangkan klien ke lingkungan keluarga dan umumnya dalam beberapa hari, minggu atau bulan di rumah, kembali dirawat dengan alasan perilaku klien yang tidak dapat diterima oleh keluarga dan lingkungan. Kualitas dan efektifitas keluarga yang memadai akan membantu dalam proses mencegah terjadinya kekambuhan klien skizofrenia (Keliat, 1996).

Keluarga perlu memahami bahwa beban yang ditimbulkan oleh gangguan jiwa sangatlah besar (Minarni \& Sudagijono, 2015). Gangguan jiwa dapat menimbulkan penderitaan yang mendalam bagi 
individu dan beban yang berat bagi keluarga. Beban ini dapat membuat gangguan pada kestabilan respon emosi pada keluarga. Hal ini terbukti dengan hasil penelitian bahwa sebagian besar respon emosi keluarga yang menolak terhadap kenyataan salah satu anggota keluarga menderita skizofrenia, mengakibatkan kekambuhan pada pasien skizofrenia itu sendiri.

Keluarga yang memperlihatkan respon emosi menolak terhadap kondisi salah satu anggota keluarganya yang menderita gangguan jiwa mencerminkan perasaan tidak menerima atas kenyataan yang dialami salah satu anggota keluarganya, sehingga keluarga tidak memberikan perawatan yang maksimal pada anggota keluarga yang menderita skizofrenia.

Respon emosi menerima merupakan bentuk dari dukungan emosional yang positif sehingga membantu proses perawatan pasien menuju kesembuhan. Dukungan emosional ini merupakan salah satu aspek penting untuk proses penyembuhan dan mengurangi kejadian kekambuhan pada pasien Skizofrenia. Dukungan emosi adalah dukungan yang diberikan keluarga sehingga keluarga dapat menjadi tempat yang kondusif, aman dan nyaman bagi pasien. Bentuk-bentuk dukungan emosi ini antara lain adanya kepercayaan, perhatian, saling mendengar, saling menyayangi satu sama lain

\section{KESIMPULAN DAN SARAN}

\section{Kesimpulan}

Respon emosi keluarga sebagian besar mempunyai respon emosi menolak yaitu sebanyak 49 responden (84,5\%). Kekambuhan pasien skizofrenia sebagian besar dalam kategori kambuh yaitu sebanyak 48 responden $(82,8 \%)$. Ada hubungan respon emosi keluarga dengan kekambuhan pasien skizofrenia di Ruang Rawat Inap Rumah Sakit Jiwa Provinsi NTB dengan nilai $\mathrm{p}=0,000$ lebih kecil dari derajat kesalahan $\alpha=$ 0,05 .

\section{Saran}

Keluarga agar lebih berperan aktif dalam perawatan pasien terutama dalam pemberian respon emosi yang positif sebagai bentuk dukungan pada pasien Skizofrenia. Keluarga agar memberikan perhatian yang cukup kepada pasien Skizofrenia, terutama dalam pengontrolan emosi dan penerimaan terhadap kondisi pasien skizofrenia sehingga meminimalkan bahkan mencegah kekambuhan pasien. 


\section{DAFTAR PUSTAKA}

Amelia, DR \& Azwar, Z (2013) Relaps pada pasien Skizofrenia. Jurnal Ilmiah Psikologi Terapan. Fakultas Psikologi Universitas Muhammadiyah Malang.

Arikunto, S.(2006). Prosedur Penelitian: Suatu Pendekatan Praktek. Edisi VI Jakarta: EGC.

Coon (2005). Psychology a Journey. USA : Thomas Wadsworth.

Depkes RI (2014). Undang Undang Kesehatan RI No 36 Tahun 2014 tentang Kesehatan Jiwa.

Friedman, dkk (2014) Buku Ajar Keperawatan Keluarga : Riset, Teori dan Pratik. Jakarta : EGC

Hawari D. 2003. Pendekatan Holistik Pada Gangguan Jiwa Skizoprenia. FKUI : Jakarta.

Hudak \& Gallo (1998). Critical Care Nursing : Holistic Approach. New York : JB Lippincolt.

Isaacs, A. (2004). Keperawatan Kesehatan Jiwa dan Psikiatrik. EGC : Jakarta.

Keliat, B.A. (2006). Peran Serta Keluarga Dalam Perawatan Klien Gangguan Jiwa. Jakarta : EGC

Keliat, B.A. dkk (2012). Buku Ajar Manajemen Kasus Gangguan Jiwa. Jakarta : EGC.

Keliat, B.A. (1996). Marah Akibat Penyakit Yang Diderita. EGC : Jakarta.

Kemenkes RI (2013). Riset Kesehatan Dasar. Jakarta : Balitbangkes Kemenkes RI

Kubler-Ross (2005). On Griev and Griefing : Finding the Meaning of Grief Through the Five Stages of Loss.

Maramis, W.F (2008). Catatan Ilmu Kedokteran Jiwa. Surabaya : Airlangga University Press

Minarni, L \& Sudagijono, J.S. (2015). Dukungan Keluarga Terhadap Perilaku Minum Obat Pada Pasien
Skizofrenia yang sedang dirawat jalan. Experienta : Jurnal Psikologi Indonesia Volume 3 No. 2.

Nuraini, HM \& Nurmaguphita, D. (2018). Hubungan Ekspresi Emosi Keluarga Dengan Kekambuhan Pada Pasien Skizofrenia di RSJ Grhasia DIY. FIK Universitas Aisyiyah Yogyakarta

Pardede, A.J., dkk (2016). Ekspresi Emosi Keluarga Dengan Frekuensi Kekambuhan Pasien Skizofrenia. Idea Nursing Journal Vol VII No 3 Tahun 2016. Program Ners Universitas Sari Mutiara Indonesia.

PPDGJ (2013). Buku Saku Diagnosa Gangguan Jiwa. Jakarta : PT Nuh Jaya.

RSJ Mutiara Sukma (2019). Laporan Tahunan Tahun 2019. Mataram : RSJ Mutiara Sukma

Saddock, B.J (2007) Anxiety Dissorder ini : Kaplan \& Sadock's Synopsis of Psyciatry Behavioral Science. 10th Edition. New York : Lippincolt Williams \& Wilkin

Sari, F (2017). Dukungan Keluarga Dengan Kekambuhan Pada Pasien Skizofrenia. Journal Pembangunan Nagari, 2(1).

Tiara, C. Dkk. (2020). Hubungan Konsep Dukungan Keluarga Dengan Tingkat Kekambuhan Pada Pasien Skizofrenia. Jurnal Ilmiah Kesehatan Sandi Husada Volume 11 Nomor 1.

WHO (2013). World Health Statistic 2013. World Health Organization.

Yosep, I \& Sutini, T (2015). Buku Ajar Keperawatan Jiwa dan Advance Mental Health Nursing. Bandung : Rafika Aditama 